\title{
STUDIES ON THE HEALING OF EXPERIMENTAL ULCER IN THE RAT II: INFLUENCE OF ANTI-INFLAMMATORY DRUGS ON THE HEALING OF THE ACETIC ACID ULCER AND THE COMPONENTS IN GASTRIC TISSUE
}

\author{
Keijiro TAKAGI and Yasuo ABE* \\ Department of Chemical Pharmacology, Faculty of Pharmaceutical Sciences, \\ University of Tokyo, Bunkyo-ku, Tokyo \\ Accepted October 4, 1973
}

\begin{abstract}
The relationship between chenical components of the injured portion in acetic acid ulcer and ulcer healing, and the influence of anti-inffammatory drugs on the ulcer were investigated herein. The hexosamine content in the corpus of normal rat stomach was decreased by a 20 day administration of $\mathrm{Na}$ salicylate or phenylbutazone. Healing of $10 \%$ acetic acid ulcer was delayed remarkably by $\mathrm{Na}$ salicylate or phenylbutazone, and hexosamine in the injured portion of the ulcer was decreased simultancously. Steroidal anti-inflammatory drugs delayed healing of the ulcer, especially in the early stage administration, where hexosamine and hydroxyproline decreased significantly. Sodium salicylate, on the contrary, delayed the ulcer healing in the early and also later stage administration. Lowercd hexosamine content in the mucosa and fall of hydroxyproline content in the stroma of the injured portion paralleled the increase of area index and grade index, respectively. In the delayed healing of the ulcer with anti-inflammatory drugs, it was clarified that changes of tissue components of the injured portion immediately after the ulcer formation play an important role in tlecr healing.
\end{abstract}

It has been observed in both humans and experimental animals that anti-inflammatory drugs injured gastric mucosa and produced hemorrhagic gastritis or gastric ulcer. The mechanism of these drugs has not been completely clarified, however, it was found that aspirin decreased the gastric acid secretion in man (1) and in the dog (2).

Phenylbutazone decreased gastric acid secretion in man (29), but no change was found in the $\operatorname{dog}$ (3). Indomethacin slightly decreased this secretion in the dog (4). On the contrary cortisone increased gastric acidity in man (5), while prednisolone brought about no change (6).

Since the reports that the gastric acid secretion is not affected by anti-inflammatory drugs were so numerous, changes in gastric mucous secretion and its biochemical properties have been observed to be the cause of lesions produced by anti-inflammatory drugs. There are a number of reports that gastric mucus decreased and its biochemical properties were changed under the influence of anti-inflammatory drugs (7-12). Although many reports were concerned with the effects of anti-inflammatory drugs on the mucus of gastric juice and the biochemical components of whole gastric mucous membrane, there are few

* Present address: Department of Chemical Pharmacology, Kyorin Chemical Laboratory, Kita-ku, Tokyo 
reports relating the ulcerogenic action of the drugs to the mucous change in an existing ulcer. The effects of steroidal anti-inflammatory drugs on the healing of thermal ulcer were histochemically sudied (13.15). Recently, the effect of anti-inflammatory drugs on the uptake of ${ }^{35} \mathrm{~S}$ in the ulcerous area of chronic experimental ulcer has been reported (16).

It has been demonstrated (17) that an early and rapid increase of hexosamine contents in the injured portion of the rat acetic acid ulcer is the most important factor for healing.

The present is concerned with the relationship between the components of the acetic acid ulcer site and the healing retardation induced by anti-inflammatory drugs. The methods used in the previous paper (17) for determination of the components were partially modified in the experiment.

\section{MATERIALS AND METHODS}

1. Influence of anti-inflammatory drugs on the gastric mucous membrane of normal rats

Anti-inflammatory drugs were administered orally to male Donryu rats, aged 81 to 83 days. On day 5, 10 and 20 after the start of administration, 6 to 10 animals were sacrificed, the stomachs were immediately isolated, fixed in $10 \%$ ncutral formalin, replacing ethanol previously used (17) and the components of gastric corpus were determined. Only on day 5 after the administration were they determined both on the antrum and corpus.

$\mathrm{Na}$ salicylate and phenylbutazone were used as non-steroidal anti-inflammatory drugs. These drugs were mixed with the powder diet in 0.5 or $0.2 \%$ respectively which was fed daily. As the chemical components of gastric tissue, hexosamine and hydroxyproline were determined. The tissue samples were separated into the mucosa and the stroma which included submucosa, muscle and serosa. These tissues were dehydrated and defatted with ethanol, acetone and ether and then dried under reduced pressure.

\section{(l) Determination of hexosamine}

About $20 \mathrm{mg}$ of the dried small tissue fragments were weighed as accurately as possible and hydrolyzed with $2 \mathrm{ml}$ of $4 \mathrm{~N} \mathrm{HCl}$ for $9 \mathrm{hr}$ at $100^{\circ} \mathrm{C}$. Hexosamine in the hydrolyzed solution was determined by Masamune's method (18).

\section{(2) Determination of hydroxyproline}

About $15 \mathrm{mg}$ of the dried small tissue fragments were weighed as accurately as possible and hydrolyzed with $1 \mathrm{ml}$ of $6 \mathrm{~N} \mathrm{HCl}$ for $12 \mathrm{hr}$ at $110^{\circ} \mathrm{C}$ in a sealed tube. Hydroxyproline in the hydrolyzed solution was determined by Robert's method (19).

2. Influence of anti-inflammatory drugs on healing of the $10 \%$ acetic acid ulcer

Male rats of Donryu strain, aged 81 to 83 days were divided into 3 groups as follows: (1) Control group with no tratment, (2) Na salicylate treated group, (3) phenylbutazone treated group.

These anti-inflammatory drugs were mixed with the powder diet in 0.5 or $0.2 \%$ respectively, and were given consecutively for 20 days, that is, 10 days before and after the ulcer production. The acetic acid ulcer was produced by the injection of $0.05 \mathrm{ml}$ of $10 \%$ 
acetic acid solution into the stomach wall of rat as reported previously (20). Animals were sacrificed on day 10 after the operaltion, the stomachs were excised, the ulcer index was estimated and then fixed in $10 \%$ neutral formalin. Histochemical observation was done on some preparations.

Uker index is expressed in terms of both the area index as the product of the length and width of a ulcer and the grade index which was divided into five grades as for the perforation in 5 or scar in 1.

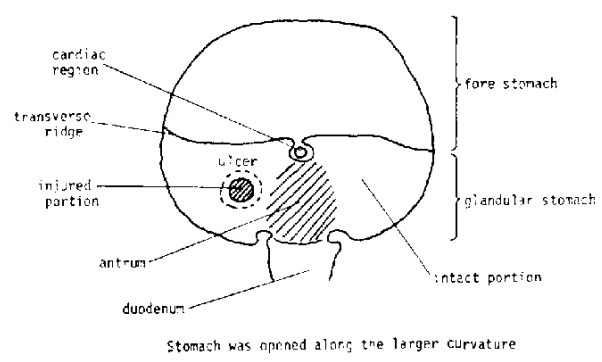

FIG. 1. Ulcerated and non-ulcerated portions in the rat with acetic acid ulcer. Injured portions include 2 to $3 \mathrm{~mm}$ of mucosal margin surrounding the ulcer and also the ulcer floor in the stroma.

As shown in Fig. 1 the injured por-

tions were separated into 2 to $3 \mathrm{~mm}$ of mucosal margin surrounding the ulcer and the stroma of ulcer floor.

The other portion was considered intact gastric tissue.

3. Influence of anti-inflammatory drugs on healing of the 3\% acctic acid ulcer

Male rats of Donryu strain, aged 68 to 70 days were divided into 3 groups: (1) control group, (2) Na salicylate treated group, (3) phenylbutazone treated group.

Details were the same as those in the previous section and acetic acid ulcer was produced by injecting $3 \%$ acetic acid on day 7 after the start of administration of the anti-inflammatory drugs.

4. Changes of the components in the gastric tissue and the delay of ulcer healing by the time anti-inflammatory drugs were administered

Prednisolone or cortisone was used as a steroidal and Na salicylate as a non-steroidal anti-inflammatory drug. Donryu strain male rats aged 87 to 89 days were used for administration of steroids and were divided as follows: (1) prednisolone in the early stage, (2) prednisolone in the later stage, (3) cortisone in the early stage, (4) cortisone in the later stage, (5) saline as a control.

The administration in the carly stage was performed daily from 3 days prior to 3 days after the operation. The later stage was 6 days starting on the 4th day after the operation. Acetic acid of $10 \%$ was used in this experiment for the production of the acetic acid ulcer. Animals were sacrificed on day 10 after the operation for the determination of gastric tissue components and ulcer indices.

Male rats of Donryu strain, aged 82 to 84 days were used for administration of nonstcroidal drugs and were divided into three groups, the early stage, later stage and control.

Administration in the carly stage was performed daily from 2 days prior to 5 days after the operation. The later stage was from the 5 th to the 11 th day after the operation. All animals were sacrificed on day 12.

5. Time course of healing of acetic acid ulcer treated with anti-inflammatory drugs

Male rats of Donryu strain, aged 84 to 90 days were divided into three groups, treated 
with Na salicylate, prednisolone and saline. Ten percent acetic acid ulcer was produced in every animal and anti-inflammatory drugs were administered s.c. every two days. Animals were sacrificed on days 7,14 and 25 after the operation and the ulcer indices and the components of gastric lissue were determined.

\section{RESULTS}

1. Influence of anti-inflammatory dungs on the gastric mucous membrane of normal rats As shown in Table 1, hexosamine content of the antral mucosa was higher than that of the corpus in normal rats. This was in good agreement with the results of Robert et al. (21), however, the hydroxyproline content of antral stroma was conversely lower than that of corpus.

The daily oral administration of phenylbutazone or Na salicylate for 10 days to normal rats resulted in a decrease in the hexosamine content in the mucosa of the corpus, while the decrease of the hexosamine content in the antral mucosa was already observed on day 5 (Table 2).

TABLE 1. Influence of $\mathrm{Na}$ salicylate or phenylbutazone on components of gastric mucous membrane in normal rats. (Day 5 )

\begin{tabular}{|c|c|c|c|c|c|c|c|}
\hline \multirow[t]{2}{*}{$\begin{array}{l}\text { Days } \\
\text { administered } \\
\text { (age of rats) }\end{array}$} & Treatment & \multicolumn{2}{|c|}{$\begin{array}{c}\text { Body weight } \\
\text { at sacrifice } \\
(g)\end{array}$} & $\begin{array}{c}\text { Drug } \\
\text { ingested } \\
\text { mgikg/day })\end{array}$ & Sample & $\begin{array}{l}\text { Stroma hydroxy- } \\
\text { proline content } \\
\text { (/g/ } 100 \mathrm{mg} \text { dry } \\
\text { tissue })\end{array}$ & $\begin{array}{c}\text { Mucosa } \\
\text { hexosamine } \\
\text { content ( } / \mathrm{g} / 100 \\
\text { mg dry tissue) }\end{array}$ \\
\hline & Control ${ }^{(n)}$ & \multicolumn{2}{|c|}{$\begin{array}{c}247.8 .8 .6 \\
(10)^{8}\end{array}$} & 0 & $\left\{\begin{array}{l}\text { Corpus } \\
\text { Antrum }\end{array}\right.$ & 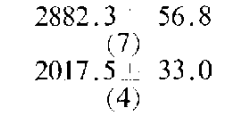 & $\begin{array}{c}2368.3 \cdot 28.9 \\
3676.7 \frac{9}{3} 70.6 \\
\left(\frac{3)}{3}\right.\end{array}$ \\
\hline \multirow[t]{4}{*}{ 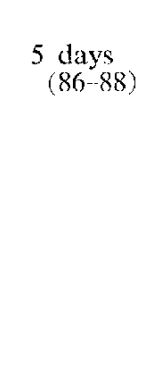 } & Na Salicylate ${ }^{(b)}$ & \multicolumn{2}{|c|}{$\begin{array}{c}233.1: 5.9 \\
(10)\end{array}$} & 232.5 & $\left\{\begin{array}{l}\text { Corpus } \\
\text { Antrum }\end{array}\right.$ & $\begin{array}{r}2651.9: 118.7 \\
1949.8 \quad 20.9 \\
(4)\end{array}$ & $\begin{array}{c}2324.0+28.6 \\
(10) \\
3191.0 \quad 68.4 \\
(3)\end{array}$ \\
\hline & $\begin{array}{l}\text { Phenyl- } \\
\text { butazone }\end{array}$ & \multicolumn{2}{|c|}{$\begin{array}{c}250.7+2.4 \\
(9)\end{array}$} & 141.2 & $\left\{\begin{array}{l}\text { Corpus } \\
\text { Antrum }\end{array}\right.$ & $\begin{array}{r}2904.3 ! \\
(7) \\
1951.8 .5 \\
(4)\end{array}$ & $\begin{array}{c}2396.7-37.6 \\
(9) \\
3242.7-32.6 \\
3)\end{array}$ \\
\hline & & \multicolumn{4}{|c|}{ Stroma } & \multicolumn{2}{|l|}{ Mucosa } \\
\hline & P-valuc & $\begin{array}{l}\text { Corpus } \\
\text { Antrum }\end{array}$ & \multicolumn{3}{|c|}{ N.S, (a) vs. (b), (c) } & \multicolumn{2}{|c|}{$\begin{array}{l}\text { N.S. (a) vs. (b), (c) } \\
0.01 \text { (a) vs. (b), (c) }\end{array}$} \\
\hline
\end{tabular}

Numbers in parentheses indicate number of determinations except those in body wh. column which indicate number of rats. Body wt. and the content of components arc expressed by mean - s.c.

Ingested drug is calculated by ingested drug (mg/kg/day).
(A) : Total diet ingested (mg)
(B) : Percent of drug in the diet
(C) : Days administered
(D) : Number of rats
(E) : Mcan body weight ( $\mathrm{kg}$ ) 
TABLE 2. Influence of $\mathrm{Na}$ salicylate or phenylbutazone on components of gastric mucous membrane in normal rats. (Day 10 and 20)

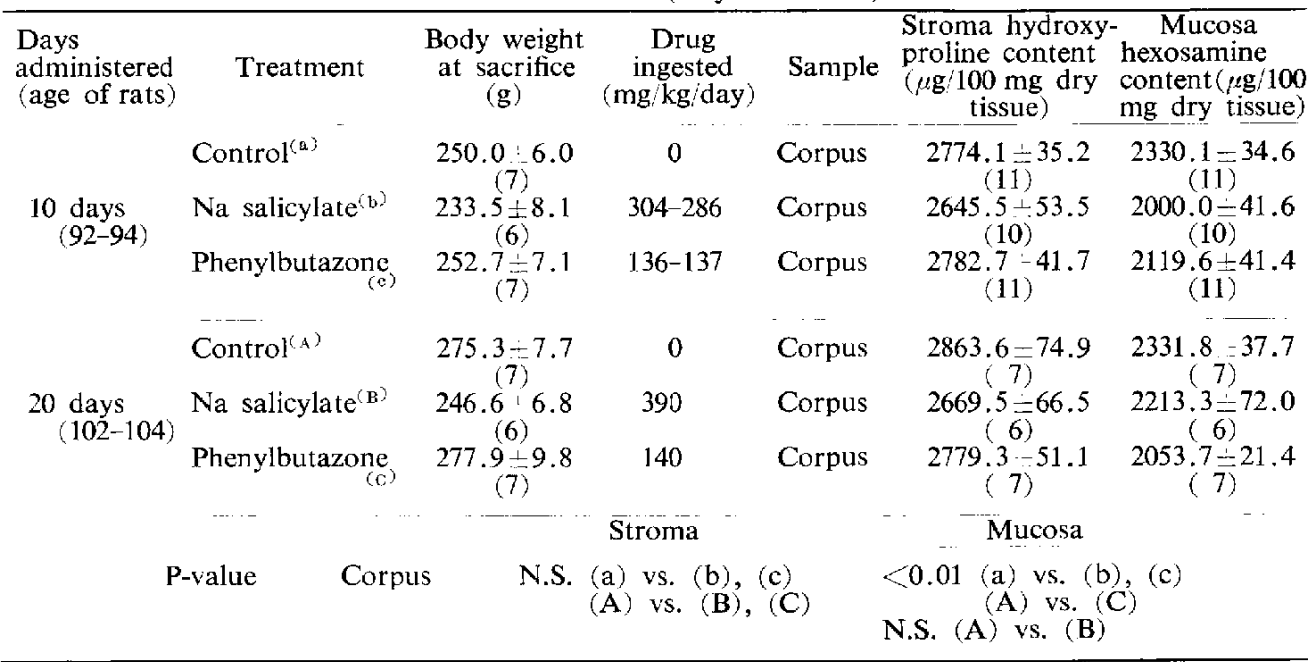

Numbers in parentheses as Table 1. Body wt. and content of components are expressed by mean + s.e.

Calculation of ingested drugs is as in Table 1.

TABLF. 3. Influence of Na salicylate or phenylbutazone administered for 20 days on the healing of $10 \%$ acetic acid ulcer in the rat.

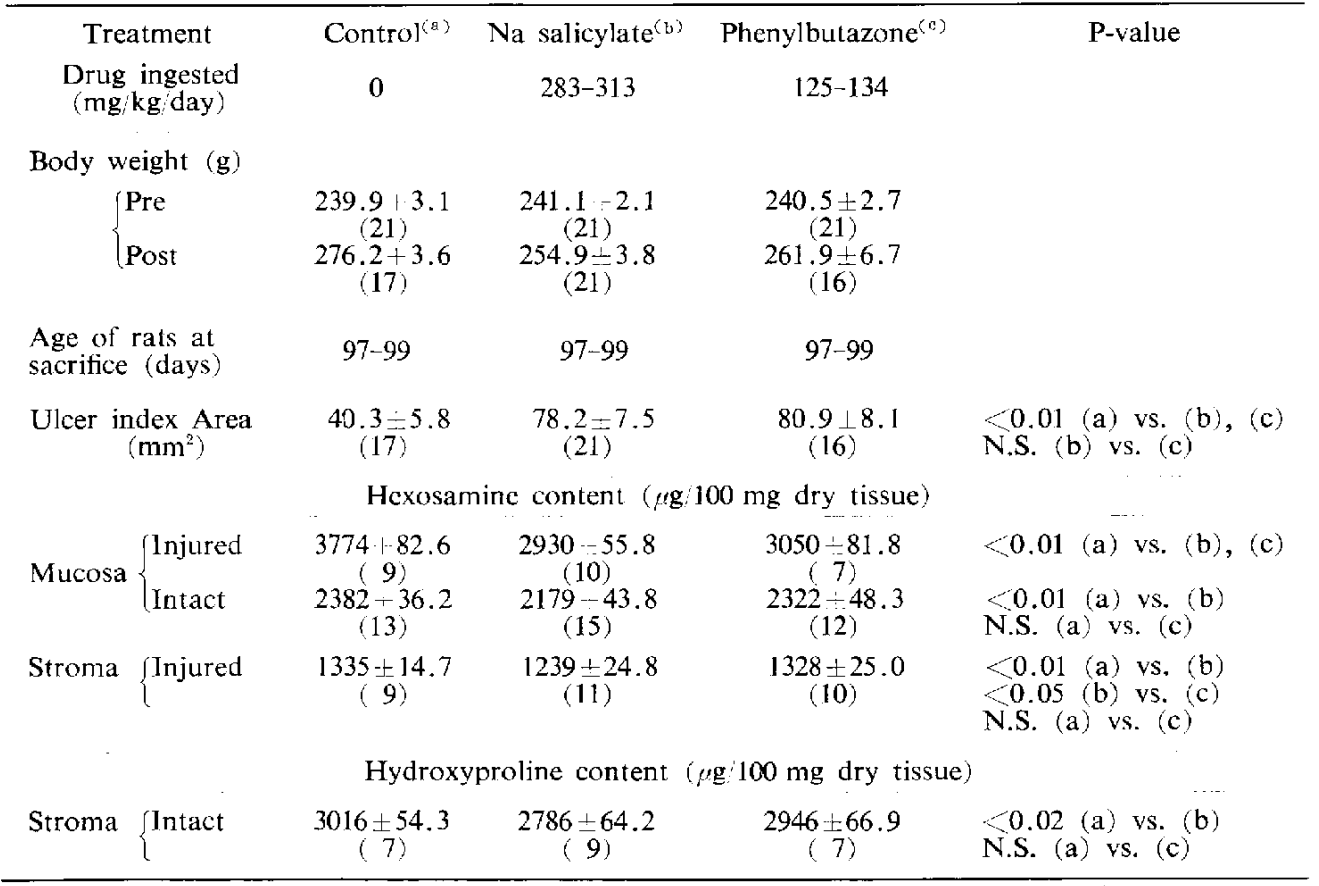

Numbers in parentheses indicate number of determinations except those in body wt. column which indicate number of rats. Injured portion included 2 to $3 \mathrm{~mm}$ of mucosal margin surrounding the ulcer and also the ulcer floor in the stroma. Animals were sacrificed on day 10 after the operation. Body wt, ulcer index and content of components are expressed by mean \pm s.e. Calculation of ingested drugs is as in Table 1. 


\section{Influence of anti-inflammatory drugs on healing of the $10 \%$ acetic acid ulcer}

The ulcer index increased remarkably with the 20 day administration of anti-inflammatory drugs. Although the hexosamine content of mucosa of the injured portion decreased by administration of the anti-inflammatory drugs, that of the stroma decreased only by $\mathrm{Na}$ salicylate administration. Hexosamine and hydroxyproline in the intact portion of stomach decreased only with $\mathrm{Na}$ salicylate administration (Table 3 ).

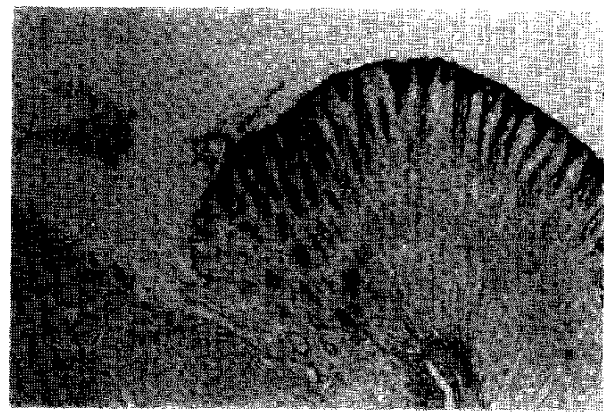

FIG. 2. Margin of $10 \%$ acetic acid ulcer treated with phenylbutazone. (on day 10)

PAS and alcian blue $\times 40$

Reduced PAS positive mucous substance was quite apparent at the edge of the ulcer.

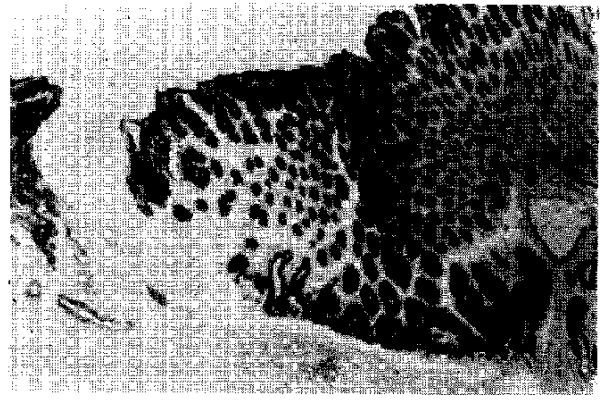

FIG. 3. Margin of $10 \%$ acetic acid ulcer without any treatment. (control) (on day 10)

PAS and alcianblue $\times 40$

A large amount of PAS positive mucous substance was quite apparent at the edge of the ulcer.

TABLE 4. Influence of anti-inflammatory drugs on the healing of $3 \%$ acetic acid ulcer in the rat.

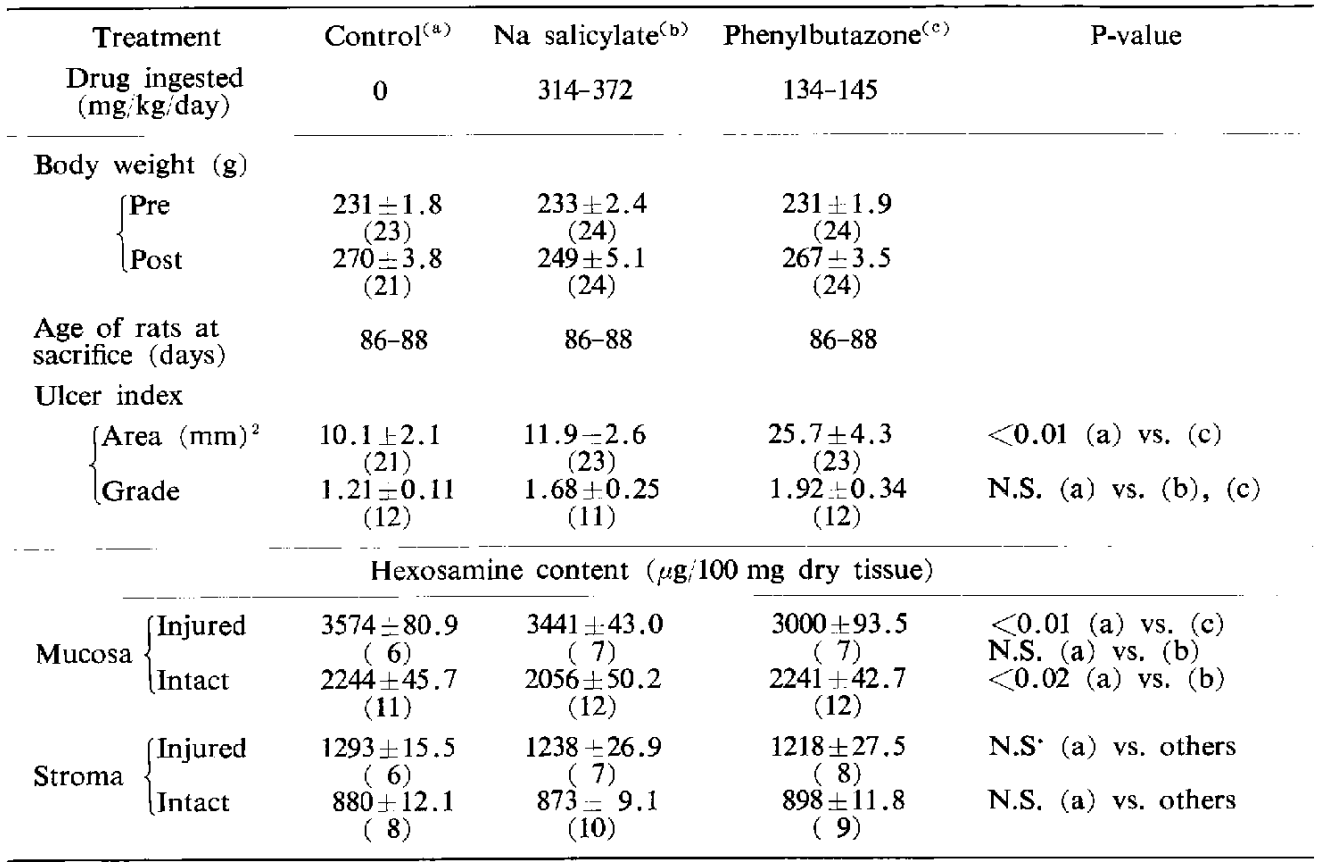

Calculation of ingested drugs is as in Table 1 . 
Under histochemical observation, the PAS and alcian blue stain in the injured portion of stomach decreased by treatment with anti-inflammatory drugs, as compared with control. At that time the reduction of the mucous substances was remarkable, especially with the phenylbutazone treatment (Figs. 2 and 3).

In addition, in the groups treated with anti-inflammatory drugs, a number of fibroblasts and capillary vascular beds was recognized in the ulcer floor as compared with the control which had already formed a scar.

\section{Influence of anti-inflammatory drugs on healing of the $3 \%$ acetic acid ulcer}

The area index of $3 \%$ acetic acid ulcer was smaller than that of $10 \%$ acetic acid ulcer and it was increased only with phenylbutazone, the healing being delayed. Simultaneously the hexosamine of the mucosa in the injured portion was decreased only with phenylbutazone (Table 4).

4. Changes of the components in gastric tissue and healing of the ulcer by the time antiinflammatory drugs were administered

As shown in Table 5, when steroidal anti-inflammatory drugs were administered in the early stage, the ulcer index was larger, the ulcer floor was deeper than those in the later

TABLE 5. Influence of the administration of prednisolone or cortisone on the healing of $10 \%$ acetic acid ulcer.

\begin{tabular}{|c|c|c|c|c|c|c|}
\hline & \multirow{2}{*}{$\begin{array}{c}\text { No } \\
\text { treatment } \\
\text { Control }^{(a)}\end{array}$} & \multicolumn{2}{|c|}{ Prednisolone treatment } & \multicolumn{2}{|c|}{ Cortisone treatment } & \multirow{2}{*}{$P$-value } \\
\hline & & $\operatorname{Pre}^{(b)}$ & Post $^{(e)}$ & $\operatorname{Pre}^{(d)}$ & $\operatorname{Post}^{(\theta)}$ & \\
\hline Number of rats & 10 & 10 & 10 & 10 & 10 & \\
\hline Mortality $(\%)$ & 0 & 70 & 30 & 0 & 0 & \\
\hline $\begin{array}{l}\text { Age of animals } \\
\text { at sacrifice (days) }\end{array}$ & $91-93$ & $91-93$ & $91-93$ & $91-93$ & $91-93$ & \\
\hline Dose $(\mathrm{mg} / \mathrm{kg})$ & 0 & 25 & 25 & 50 & 50 & \\
\hline Admini- $\{$ Days & - & 6 & 6 & 6 & 6 & $<0.01$ (a) vs. (b) \\
\hline stration $l_{\text {Route }}$ & s.c. & s.c. & s.c. & s.c. & s.c. & $\{<0.05$ (a) vs. (c) \\
\hline $\begin{array}{l}\text { Ulcer } \\
\text { index }\end{array}\left\{\begin{array}{l}\text { Area } \\
\left(\mathrm{mm}^{2}\right)\end{array}\right.$ & $\underset{(10)}{27.0 \div 3.5}$ & $\begin{array}{c}78.7 \pm 14.1 \\
(3)\end{array}$ & $\begin{array}{c}40.4 \pm 5.1 \\
(7)\end{array}$ & $\begin{array}{c}42.4 \pm 6.9 \\
(10)\end{array}$ & $\begin{array}{c}24.3 \pm 3.1 \\
(10)\end{array}$ & $\begin{array}{l}\text { (d) vs. (e) } \\
\text { N.S. (a) vs. (d), (e) }\end{array}$ \\
\hline Grade & $\begin{array}{c}1.75 \div 0.20 \\
(10)\end{array}$ & $\begin{array}{l}4.0 \\
(3)\end{array}$ & - & $\begin{array}{c}3.60 \pm 0.34 \\
(10)\end{array}$ & $\begin{array}{c}2.40+0.26 \\
(10)\end{array}$ & $\left\{\begin{array}{l}<0.01 \text { (a) vs. (d) } \\
\langle 0.02 \text { (d) vs. (e) } \\
\text { N.S. (a) vs. (e) }\end{array}\right.$ \\
\hline $\begin{array}{lll}- & \cdots & -\end{array}$ & \multicolumn{5}{|c|}{ Hexosamine content ( $\mu \mathrm{g} / 100 \mathrm{mg}$ dry tissue) } & \\
\hline \multirow[t]{2}{*}{ Mucosa } & $\begin{array}{c}2788 \\
(2) \\
2213+43.2 \\
(9)\end{array}$ & - & $\begin{array}{c}1718 \\
(2) \\
1409 \pm 65.6 \\
(4)\end{array}$ & $\begin{array}{c}2585 \\
(2) \\
1979 \stackrel{\stackrel{2}{=}}{=} 2.9 \\
(9)\end{array}$ & $\begin{array}{c}2941 \\
(2) \\
2059 \pm 87.9 \\
(9)\end{array}$ & $\left\{\begin{array}{l}<0.01(a) \text { vs.(c),(d) } \\
\text { N.S. (a) vs. (e) } \\
\text { (d)vs.(e) }\end{array}\right.$ \\
\hline & \multicolumn{5}{|c|}{ Hydroxyproline content ( $\mu \mathrm{g} / 100 \mathrm{mg}$ dry tissue $)$} & \\
\hline Stroma $\{$ Injured & $\begin{array}{c}3041 \pm 131.9 \\
(6)\end{array}$ & 一 & - & $\begin{array}{c}2380 \div 77.4 \\
(13)\end{array}$ & $\begin{array}{c}3363 \pm 71.8 \\
(6)\end{array}$ & $\left\{\begin{array}{l}<0.01 \text { (a) vs. (d) } \\
\text { (d) vs. (e) } \\
\text { N.S. (a) vs. (e) }\end{array}\right.$ \\
\hline
\end{tabular}

Pre indicates the administration of an anti-inflammatory drug in the early stage. Post is the administration of the drug in the later stage. The grade index is expressed from 5 to 1 respectively as for the perforation in 5 or scar in 1 . Ulcer index and content of components are expressed by mean \pm s.e. 
stage administration and delayed healing was observed. When cortisone was administered in the early stage of the ulceration, hydroxyproline content in the injured stroma of ulcer floor was reduced remarkably, but it was not reduced in the later stage administration. Simultaneously, hexosamine of the mucosa in the injured portion tended to decrease but insignificantly with cortisone administration in the early stage, while in the intact portion, hexosamine of the mucosa decreased significantly with the same treatment. Prednisolone caused perforation in most stomachs, especially in the early stage administration. When Na salicylate was administered, the area index of ulcer increased in both the early and later stage administration (Table 6). The grade index of ulcer only increased significantly in the early stage administration. Simultaneously in this injured portion, hydroxyproline of stroma decreased in the early stage administration, while on the contrary, hexosamine of mucosa decreased in the later stage.

Hexosamine content of the mucosa of the intact portion showed a similar tendency to that of the injured portion, but at a far lower level.

TABLE 6. Influence of the administration of $\mathrm{Na}$ salicylate on the healing of $10 \%$ acetic acid ulcer.

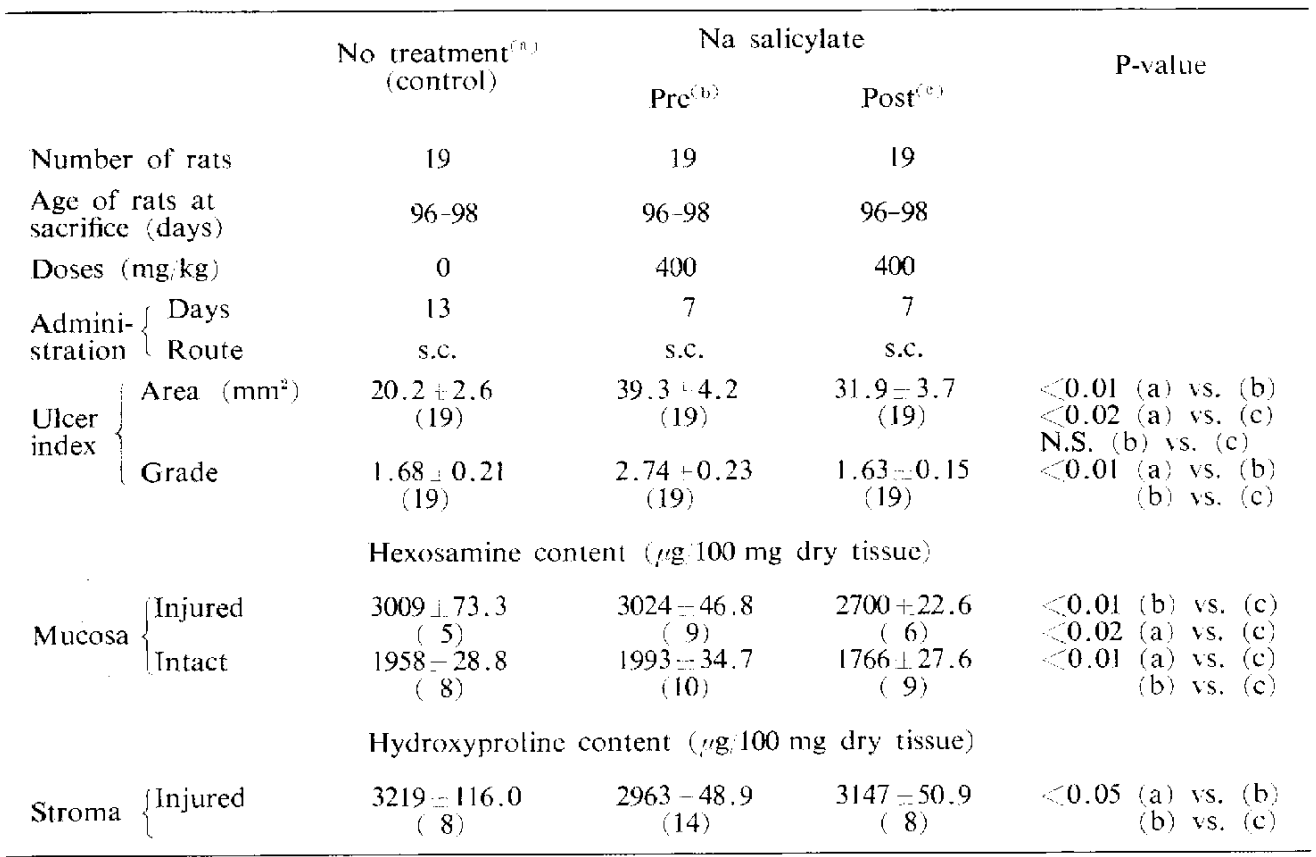

See Table 5 .

5. Time course of acotic acid ulcer healing treated with anti-inflammatory diugs

The area index of ulcer increased remarkably on day 7 after the operation in the control groups and recovered gradually to the control level, however, Na salicylate markedly delayed this recovery. The grade index of ulcer increased significantly in the groups treated with anti-inflammatory drugs (Table 7). 
TABLE 7. Progressive changes of ulcer indices in the rat with $10 \%$ acetic acid ulcer with anti-inflammatory drugs.

Group

(a)
Uleer index in the grade

(b)
P-value

(c)

Treatment Saline (control) Na salicylate Prednisolone

Days after operation

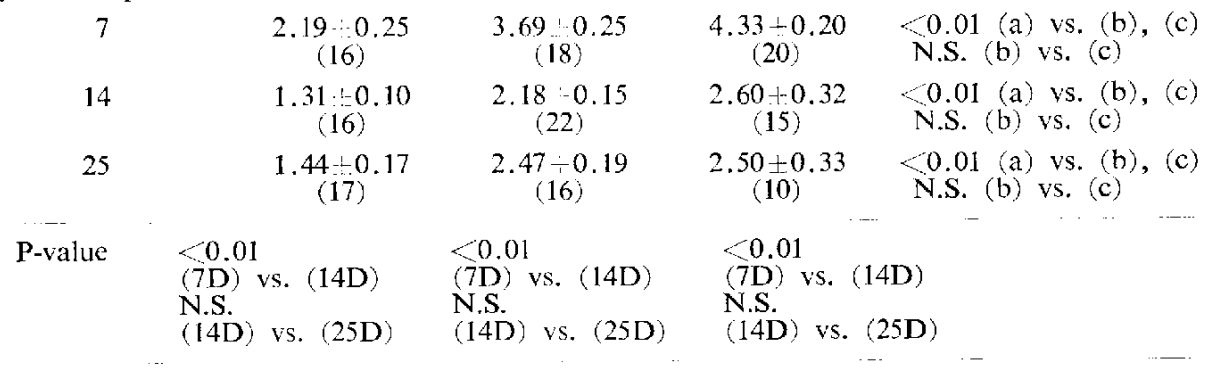

Group

(a)
Ulcer index in the area

(b) (c)

P-value

Treatment Saline control) Na salicylate Prednisolone

Days after operation

\begin{tabular}{|c|c|c|c|c|}
\hline 7 & $\begin{array}{l}36.7+5.2 \\
(16)\end{array}$ & $\begin{array}{c}62.51 .5 .4 \\
(18)\end{array}$ & $\underset{(20)}{56.2+5.7}$ & $\begin{array}{l}0.01 \text { (a) vs. (b) } \\
0.05 \text { (a) vs. (c) } \\
\text { N.S. (b) vs. (c) }\end{array}$ \\
\hline 14 & $\frac{15.3+2.4}{(16)}$ & $\frac{39.8}{(22)} 4.2$ & $\begin{array}{c}25.3 \div 4.6 \\
(15)\end{array}$ & $\begin{array}{l}0.01 \text { (a) vs. (c) } \\
\text { (b) vs. (c) } \\
\text { N.S. (a) vs. (c) }\end{array}$ \\
\hline 25 & $18.41 .4 . I$ & $\begin{array}{c}27.2+3.0 \\
(16)\end{array}$ & $\begin{array}{c}19.3 \div 4.6 \\
(10)\end{array}$ & N.S. (a) vs. others \\
\hline P-value & $\begin{array}{l}(0.01 \\
(7 D) \text { vs. (14D) } \\
\text { N.S. } \\
\text { (14D) vs. (25D) }\end{array}$ & $\begin{array}{l}0.01 \\
(7 \mathrm{D}) \text { vs. (14D) } \\
(14 \mathrm{D}) \text { vs. 25D) }\end{array}$ & $\begin{array}{l}0.01 \\
(7 D) \text { vs. } \\
\text { N.S. } \\
\text { (14D) vs. }\end{array}$ & \\
\hline
\end{tabular}

(7D), (14I)), (25D): 7th day, 14th day, 25th day after the operation.

Numbers in parentheses indicate number of rats.

Uker indices are expressed by mean + s.e.

Na salicylate, prednisolone and saline were administered s.c. every two days for 7,14 and 25 days.

Animals were sacrificed on the $7 \mathrm{~h}, 14 \mathrm{th}$ and 25 th day after the operation.

As shown in Table 8, hexosamine content in injured mucosa decreased by administration of anti-inffammatory drugs on day 7 after the operation. Also hydroxyproline in the injured stroma of the ulcer floor decreased on day 7 after the operation and this tendency remained until day 14 after the operation in the case of both anti-inflammatory drugs.

\section{DISCUSSION}

Robert et al. (21) suggested, according to the animal experiments, that hexosamine of mucous membrane represents the mucus content, and in turn showed that hexosamine in the antrum was higher than that in the corpus and further that for this difference ulcers 
TABLE 8. Progressive changes of the components in injured stroma and mucosa of rat stomach with $10 \%$ acetic acid ulcer with anti-inflammatory drugs.

Hexosamine content ( $/ \mathrm{g} 100 \mathrm{mg}$ dry tissue)
Group
(a)
(b)
(c)
P-value

Treatment Saline (control) $\mathrm{Na}$ salicylate Prednisolone

Days after operation

\begin{tabular}{|c|c|c|c|c|}
\hline 7 & $\begin{array}{c}2818+t 73.6 \\
(6)\end{array}$ & $\begin{array}{c}2465 \pm 46.0 \\
(7)\end{array}$ & $\underset{(7)}{2493} \frac{1}{7} 60.0$ & $\begin{array}{l}0.01 \text { (a) vs. (b), (c) } \\
\text { N.S. (b) vs. (c) }\end{array}$ \\
\hline 14 & $\left.3344 \pm \frac{1}{5}\right)(68.0$ & $\begin{array}{c}3038-60.2 \\
(7)\end{array}$ & $\left.2787 \frac{-92.7}{5}\right)$ & $\begin{array}{l}<0.05 \text { (a) vs. (c) } \\
\text { (b) vs. (c) } \\
\text { N.S. (a) vs. (b) }\end{array}$ \\
\hline 25 & $\begin{array}{c}3529 \pm 190.7 \\
(5)\end{array}$ & $\begin{array}{c}2840-77.9 \\
(5)\end{array}$ & $\begin{array}{c}32011.189 .0 \\
(3)\end{array}$ & $\begin{array}{l}0.02 \text { (a) vs. (b) } \\
\text { N.S. (a) vs. (c) } \\
\text { (b) vs. (c) }\end{array}$ \\
\hline \multirow[t]{2}{*}{ P-value } & $\begin{array}{l}\langle 0.02 \\
(7 \mathrm{D}) \text { vs. }(14 \mathrm{D}) \\
\text { N.S. } \\
(14 \mathrm{D}) \text { vs. }(25 \mathrm{D})\end{array}$ & $\begin{array}{l}<0.01 \\
(7 \mathrm{D}) \text { vs. }(14 \mathrm{D}) \\
\text { N.S. } \\
(14 \mathrm{D}) \text { vs. }(25 \mathrm{D})\end{array}$ & \multicolumn{2}{|c|}{$\begin{array}{l}\langle 0.02 \\
\text { (7D) vs. (14D) } \\
\text { N.S. } \\
(14 \mathrm{D}) \text { vs. (25D) }\end{array}$} \\
\hline & \multicolumn{3}{|c|}{ Hydroxyproline content ( $\mathrm{g} 100 \mathrm{mg}$ dry tissue) } & \multirow[b]{2}{*}{ P-value } \\
\hline Group & (a) & & (c) & \\
\hline Treatment & Saline (control) & $\mathrm{Na}$ salicylate & Prednisolone & \\
\hline \multicolumn{5}{|c|}{ ys after operation } \\
\hline 7 & $\frac{2814+54.3}{(8)}$ & $\begin{array}{c:c}2069 & 182.5 \\
(9)\end{array}$ & $\frac{1880+125.9}{(5)}$ & $\begin{array}{l}\$ 0.01 \text { (a) vs. (b), (c) } \\
\text { N.S. (b) vs. (c) }\end{array}$ \\
\hline 14 & $\begin{array}{c}3512 \div 86.8 \\
(7)\end{array}$ & ${ }^{3275-40.5}$ & $\frac{3239+223.0}{(6)}$ & $\begin{array}{l}<0.02 \text { (a) vs. (b) } \\
\text { N.S. (a) vs. (c) } \\
\text { (b) vs. (c) }\end{array}$ \\
\hline 25 & $\begin{array}{c}3909+58.3 \\
(7)\end{array}$ & $\begin{array}{c}4035 \div-48.4 \\
(6)\end{array}$ & $\frac{3796-203.8}{(7)}$ & N.S. (a) vs, (b), (c) \\
\hline P-value & $\begin{array}{l}0.01 \\
(7 D) \text { vs. }(14 D) \\
(14 D) \text { vs. }(25 D)\end{array}$ & $\begin{array}{l}\text { (7D) vs. }(14 \mathrm{D}) \\
(14 \mathrm{D}) \text { vs. }(25 \mathrm{D})\end{array}$ & $\begin{array}{l}\text { (0.01 } \\
\text { (7D) vs. } 1 \\
\text { N.S. (14D) }\end{array}$ & $\begin{array}{l}\text { D) } \\
\text { vs. (25D) }\end{array}$ \\
\hline
\end{tabular}

(7D), (14D), (25D) : 7th day, 14th day, 25th day after the operation.

do not develop in the antrum (22).

In addition, it was reported $(23,24)$ that hexosamine in the nucous membrane was reduced by restraint to a greater extent in the antrum than in the corpus.

In the present experiment, hexosamine content of mucosa was found to be higher and also hydroxyproline in the stroma to be lower in the antrum than in the corpus of normal rats. The eflect of non-steroidal anti-inflammatory drugs on hexosamine content in antral mucous membrane was drastic and this phenomena may be similar to that observed under restraint stress.

The fact that gastric nucous secretion decreased with steroidal anti-inflammatory drugs has been widely reported $(8,22,2527)$. In this experiment the reduction of the hexosamine content in the injured portion of acetic acid ulcer was remarkable and the healing was delayed in the early stage administration of a steroidal drug. These drugs also reduced the hydroxyproline level of the ulcer floor, which became deeper, followed 
by the increase of grade index of ulcer, which was different from the ulecr aggravated by $\mathrm{Na}$ salicylate. Na salicylate delayed the healing as expressed in area index in both the early and later stage administrations, but the grade index was increased significantly only in the early stage administration, when it had only been applied for 7 days. The increase of area index may be related to the lowered hexosamine content in mucosa and the decrease of hydroxyproline in stroma, and the increase of grade index solely to the fall of hydroxyproline content in the stroma. It must be mentioned here that 20 days administration of $\mathrm{Na}$ salicylate or phenylbutazone aggravated acetic acid ulcer and that the hexosamine content of the gastric mucosa of the injured portion was lowered consistently.

Martin et al. (28) reported that one of the mechanisms of gastric mucosal injury by cortisone and ACTH may be a reduced rate of renewal of surface epithelial cells and that aspirin and phenylbutazone, on the other hand, appear to affect the gastric mucosa in such a way that shedding of surface cells increases without a concomitant increase in the rate of cell renewal.

Schönhöfer et al. (30) reported that the activity of glucosamine-6-phosphate synthesizing enzyme in gastric mucous membrane of the rat was specifically inhibited by phenylbutazone or $\mathrm{Na}$ salicylate, that the latter exceeded the former in this inhibitory action in spite of a lighter gastric lesion than the former, and that the enzyme activity and the intensity of the gastric lesion produced by them were not parallel. Glucosamine-6-phosphate synthesizing enzyme activity appears to parallel the hexosamine content of tissue. In our experiment, it was demonstrated that hexosamine in the intact gastric portion of the rat with an acetic acid ulcer was reduced by phenylbutazone or Na salicylate with the sume pattern as enzyme actiyity inhibition, but in the injured portion, the mucosal hexosamine content was dissimilar to the enzyme activity but closely paralleled the ulcer index (Table 3, 4). This is in good agreement with the results in our previous paper (17).

These observations suggest that the mucosal hexosamine and stromal hydroxyproline content in the injured portion play an important role in ulcer healing, and also demonstrate the difference between steroidal and non-steroidal anti-inflammatory drugs regarding retardation in uker healing.

\section{REFERENCES}

1) Wivklimav, E.I. AND Summirskill, W.t.J.: Gastroenterology 40, 56 (1961)

2) Shaw, A.H. AND Milton, G.W.: Gut 5, 230 (1964)

3) Srafl, H.L.: Am. J. Med. 29, $780(1960)$

4) Nicolort, D.M.: Arch. Sirg. 97, 809 (1968)

5) Gray, S.J., Ramsay, C., Rhativitlin, R.W. and Benson, J.A.: Gastroenterology 25, 156 (1953)

6) Beck, 1.T., Flitoher, H.W., MCKenna, R.D. n.vo Griff, H.: Gasmoenterology 38, 740 (1960)

7) Mengivy, R. ANd Masters, Y.F.: Surgery Gynec. Obstet. 120, 92 (1965)

8) Minguy, R. And Masteks, Y.F.: Surgery 54, 19 (1963)

9) Desbailufts, L. nvd Menguy, R.: Am. J, dig. Dis. 12, 582 (1967)

10) Mlinguy, R. and Disballelis, L.: Proc. Soc. exp. Biol. Med. 125, 1108 (1967)

11) Menguy, R. aNo Desbaillets, L.: Am. J. dig. Dis, 12, 862 (1967)

12) Prerer, K.H.: Arch. int. Phamacodyn. Ther. 176, 337 (1968) 
13) JANowiTz, H.D.: Gastroenterology 34, 11 (1958)

14) Janowitl, H.D., Wemstein, V.A. and Hollandir, F.: Fidn. Proc. 14, 79 (1955)

15) Coli, V., Silvestrivi, B. and Dordon, F.: Lip. Mol. Pufh. o, 68 (1967)

16) Ilayashi, T.: Japan. J. Gastroem. 67, 27 (1970)

17) TakaGi, K. AND ABr, Y.: Folia phamacol, japon. 68, 504 (1972) (in Japanese)

18) Masamuni, H. and Yosizawa, Z.: Tohoka J. Lixp. Met. 65, 169 (1957)

19) Robert, E.N. AND MiLAN, L.A.: J. biol. Chem. 184, 229 (1950)

20) Takagi, K., Okaibl, S. ANd Saziki, R.: Japam. J. Pharmacol. 19, 418 (1969)

21) Robert, A., Bayfr, R.B. Ad Nezamis, J.E.: Gastroentorology 45, 740 (1963)

22) Robert, A.: Fed. Proc. 22, 663 (1963)

23) Ronirt, $A$. ani Nizamis, J.E.: J. Pharm. Pharmacol. 16, 690 (1964)

24) Robirt, A. and Nizamis, J.L.: Proc. Soc. exp. Biol. Met. 100, 596 (1959)

25) Hitzbergier, A.L. a`d Glass, L.: J. Lab. clin. Med. 59, 575 (1962)

26) Kowalewski, K.: Proc. Soc. exp. Biol. Med. 101, 147 (1959)

27) Baklir, B.L. And Bridgman, R.M.: Am, J. Anat, 94, 363 (1954)

28) Martin, M. AND MENGUY, R.: Gastrochterology 58, 329) (1970)

29) Bonfics, S.J.P.: Bull. Soc. Med. Hop. (Paris) 71, 114 (1955)

30) Sohönholer, P. And Perry, K.H.: Med. Pharmacol. Exp. 17, 175 (1967) 